Retraction

\title{
Retraction: Zhang M. et al. Estimation of Net Primary Production Using Landsat 8 Time Series in a Heavily Urbanized Area, Central China. Remote Sensing. 2019, 11(2), 133
}

\author{
Meng Zhang ${ }^{1,2,3, *}$, Hui Lin ${ }^{1,2,3, *}$, Hua Sun ${ }^{1,2,3}$ and Yaotong Cai ${ }^{1,2,3}$ \\ 1 Research Center of Forest Remote Sensing \& Information Engineering, Central South University of Forestry \\ \& Technology, Changsha 410004, China \\ 2 Key Laboratory of Forestry Remote Sensing Based Big Data \& Ecological Security for Hunan Province, \\ Changsha 410004, China \\ 3 Key Laboratory of State Forestry Administration on Forest Resources Management and Monitoring in \\ Southern Area, Changsha 410004, China \\ * Correspondence: mengzhang@csu.edu.cn (M.Z.); linhui@csuft.edu.cn (H.L.)
}

We have been made aware that the experimental data, methodological framework, and description of the corresponding sections in this article are similar to those of another publication (in Chinese with an English abstract) by the first author himself, Zhang and Zeng [1], and Dr. Zeng was not aware of this article [2] submitted to Remote Sensing.

MDPI is a member of the Committee on Publication Ethics and takes its responsibility to enforce strict ethical policies and standards very seriously. To ensure the addition of only high-quality scientific works to the field of scholarly publication, the present paper [2] is retracted. The article is retracted with the agreement of all authors. We apologize to the readership of Remote Sensing for any inconvenience caused.

\section{References}

1. Zhang, M.; Zeng, Y. Net primary production estimation by using fusion remote sensing data with high spatial and temporal resolution. J. Remote Sens. 2018, 22, 147-156.

2. Zhang, M.; Lin, H.; Sun, H.; Cai, Y. Estimation of Vegetation Productivity Using a Landsat 8 Time Series in a Heavily Urbanized Area, Central China. Remote Sens. 2019, 11, 133. [CrossRef]

(C) 2019 by the authors. Licensee MDPI, Basel, Switzerland. This article is an open access article distributed under the terms and conditions of the Creative Commons Attribution (CC BY) license (http://creativecommons.org/licenses/by/4.0/). 